\title{
Influence of water column chlorophyll concentration on bathymetric estimations in the lagoon of New Caledonia,
} using several MERIS images

\author{
Audrey MINGHELLI-ROMAN ${ }^{1}$, Cécile DUPOUY ${ }^{2}$ \\ ${ }^{1}$ University Sud Toulon Var, LSIS, UMR CNRS 6017, Av G. Pompidou, BP 56, 83162, La \\ Valette du Var, France \\ 2 Aix-Marseille University, University Sud Toulon-Var, CNRS/INSU, IRD, Mediterranean \\ Institute of Oceanography MIO, UM 110, Centre IRD de Nouméa, BP A5, 98848, Nouméa, \\ New Caledonia
}

\begin{abstract}
An estimation of bathymetry in the optically complex lagoon of New Caledonia was performed from multispectral satellite images. Bathymetric estimation was obtained with different Medium Resolution Imaging Spectrometer (MERIS) images acquired at different dates. The method is based on the rotation of a pair of spectral bands (red and green bands). One of the resulting images is only depth-dependent when the other is reflectance dependant. A comparison was made with a compilation of bathymetric data from Institut de Recherche pour le Développement (IRD) Nouméa measurements. This study shows the influence of the variation of water composition, and then of the diffuse attenuation, on bathymetric results. The variation of chlorophyll concentration, correlated with variation of diffuse attenuation, explains the error of the estimation map. The results show that this method remains valid under a low $\left(<1 \mathrm{mg} \cdot \mathrm{m}^{-3}\right)$ and constant concentration $(<10 \%$ of variation) of chlorophyll to limit the variation of RMSE in the image on the bathymetric estimation $(<15.5 \%)$.
\end{abstract}


Index Terms - Bathymetry, diffuse attenuation, coastal zone, lagoon, MERIS.

\section{Introduction}

In many regions, sea depth changes because of erosion and sedimentation processes and bathymetry must often be updated. Bathymetric surveying of shallow sea water is often performed by conventional ship-based or plane-based acoustic surveys. However, this technique requires heavy and expensive equipment and missions [1] as well as time consuming for data processing [2].

In the 1970's, the use of aerial or satellite remote sensing images appeared as a new alternative to the classical methods of bathymetric measurements for depths between 0 and 30 m. In coastal areas, bathymetric maps were often anaccurate or non-existent. Generally, these areas offer favourable conditions (clear and shallow waters) and a great potential of resources. In the 1970's with the new spatial programs, different studies were carried out ([3], [4] and [5]) in order to evaluate the potential of remote sensing to provide bathymetric maps.

The first approach [6] was simply based on the log-transform of 2 spectral bands and a 2Drotation to estimate bathymetry [7]. This technique has often been applied to high spatial resolution imagery such as Landsat/MSS [8], SPOT/HRV [9], and IKONOS [10] images because they have been made widely available even if they are not dedicated and specified for marine coastal shallow area applications. The advantage of this approach is that it provides a continuous depth map, the sea bed cover and the bottom reflectance are not required. But an assumption is made on diffuse attenuation considered as constant therefore limiting the requirements to obtain an accurate bathymetric map. 
In the last decade, approaches for mapping bathymetry in optically shallow water bodies have evolved to non-linear optimization of semianalytical models ([11], [12], [13], [14]) and comparative methods of spectral library matching ([15] and [16]) from hyperspectral data and modelled data. In some cases these approaches can also be used to produce corrected substratum reflectance spectra and to quantify concentration of organic and inorganic water constituents.

Adler-Golden et al. [11] present an algorithm similar to that of Lee et al. [14]. However, it makes the simplifying assumption of constant water optical properties within the scene. McIntyre et al. [17] presented an application of the Lee et al. [14] inversion modelling approach to clear waters which included a quantitative comparison of model-derived depth with high resolution multi-beam acoustic bathymetry data.

Several authors recently extended the method developed by Lee et al. ([13], [14])) by incorporating linear un-mixing of the benthic cover. Giardino et al. [18] used two substrate classes (bare sand and submerged macrophytes) for the littoral zone of a lake, while Goodman and Ustin [19] and Klonowski et al. [20] integrated a semi-analytical inversion model with a linear un-mixing of three substratum types for coral reef environments.

Goodman et al. [21] quantified the influence of atmospheric and sea-surface corrections on the accuracy of the retrieval of bottom depth and reflectance using a semi-analytical model. Brando et al. [22] presented the quantitative comparison of model-derived depth for coastal water with high resolution multi-beam acoustic bathymetry data and showed that the precision of the bathymetry retrieval was a function of the contribution of substratum to the remote sensing signal. The accuracy was also a function of the calibration of the hyperspectral 
imagery, the parameterization of the atmospheric correction and the parameterization of the model adopted for the retrieval.

The advantage of these last approaches is that the attenuation is not assumed to be constant (because the water composition is not supposed to be constant) but the reflectance of the sea bed is required. It also provides quantified maps for each parameter because the various combinations of inputs must be operated for discrete inherent optical properties and depths. A drawback of these methods is the non-unique solution that can be found in the database: 2 combinations of different input parameters of the radiative model can provide the same spectrum and confusion can then be made in the closest spectrum choice in the spectral library. For example, a dark bottom with a turbid water column can provide the same surface reflectance as a sandy bottom with clear water column. This phenomenon can also naturally influence the depth estimation.

Because reflectance of the sea bed is not always known and because sometimes continuous depth map is required, we choose in this paper to use the approach based on the log-transform of 2 spectral bands, to analyse its limits and to provide best conditions for its use. We then study the influence of the attenuation variation due to the chlorophyll water content on the depth estimation accuracy in the lagoon of New Caledonia.

The New Caledonian lagoon $\left(22.177 \mathrm{~km}^{2}, 25 \mathrm{~m}\right.$ mean depth) lies in the Southwester Tropical Pacific around $21^{\circ} \mathrm{S}$ and $166.5^{\circ} \mathrm{E}$, with a heterogeneous bathymetry due to a complex geomorphology and a variety of different bottom colors. It is largely connected to the open ocean in the south part of the lagoon, but only by narrow passes in the southwest part of the lagoon. Exchanges with the sea can modify the phytoplanktonic assemblage in the central 
lagoon, characterized by oligotrophic to mesotrophic waters (yearly average chlorophyll-a concentration of $0.25 \pm 0.01 \mathrm{mg} \mathrm{m}-3$ ) [23, 24]. With relatively low river inputs and a low turbidity range compared with other tropical lagoons $(0.20-16 \mathrm{~g} \mathrm{~m}-3$, [25], its trophic state is linked to spatial variations in flushing times $[26,27]$. The variability of the turbidity was studied [25] and the optical properties and chlorophyll concentration were examined as a function of bathymetry [28]. Indeed, water transparency can change due to the variability of water composition (chlorophyll, mineral suspended and dissolved organic matters).

The MERIS sensor was designed for sea color observation, with a $300 \mathrm{~m}$ spatial resolution, 15 spectral bands, over a $1150 \mathrm{~km}$ swath width and a 3 day revisit period [29] more adapted to coastal zone monitoring than previous sensors like SeaWiFS ( 8 bands, $1 \mathrm{~km}$ resolution) or MODIS (8 bands, $500 \mathrm{~m}$ resolution). Compared to high spatial resolution sensors like SPOT, Landsat/ETM or IKONOS, MERIS can be preferred for its large swath to cover a large study area.

Seven MERIS images were acquired full resolution on 8/1/2004, 18/6/2008, 13/07/2008, 20/10/2008, 2/11/2008, 17/1/2009 and 24/2/2009. The water conditions are temporally variable in the lagoon and the water composition is then not the same for all the acquisitions, i.e. the water diffuse attenuation varies between the images. In this paper, the methodology used for bathymetric estimation is recalled. We also present the test images and the validation data. The results obtained for all images are presented, compared and discussed.

\section{Method}

The original method [6] consists in measuring the water attenuation by estimating the deep water reflectance and the water depth with the assumption that the bottom reflectance 
attenuation is only due to the water column layer thickness and then to the depth. The water attenuation is also assumed to be homogenous. The water attenuation model [30] is given by (1).

$$
\rho_{s}(\lambda)=\left[\rho_{b}(\lambda)-\rho_{w}(\lambda)\right] e^{-2 k(\lambda) z}+\rho_{w}(\lambda)
$$

with

$\rho_{s}$ the surface reflectance [dimension less],

$\rho_{b}$ the seabed reflectance [dimension less],

$\rho_{w}$ the deep water reflectance [dimension less],

$k$ the diffuse attenuation $\left[\mathrm{m}^{-1}\right]$,

$z$ the depth, [m].

$\rho_{s}$ is known (values of the original image), $\rho_{w}$ can be obtained under a Region of Interest (ROI) of deep water, $\rho_{b}$ does not need to be known, $k$ needs to be estimated and $\mathrm{z}$ is the final unknown.

Eq. (1) is an approximate radiation transport equation, $k$ is assumed to be independent of depth and the diffuse attenuation for the downwelling irradiance equals the diffuse attenuation for the upwelling radiance.

In clear waters the diffuse attenuation is weak for short wavelengths and increases after 570 $\mathrm{nm}$ because of the strong absorption by water molecules at high wavelengths [31]. For waters more charged in phytoplankton and suspended organic matter, attenuation is higher at short wavelengths, which are more influenced by the absorption of the cited constituents. The diffuse attenuation estimation requires different locations in the study area (at least 2) covered by the same seabed, at different depths (not quantitatively known). For these locations, pixels 
provide radiometric values for each spectral band. The two useful wavelengths for this study are located in the green $\left(\lambda_{\mathrm{g}}\right)$ and the red region $\left(\lambda_{\mathrm{r}}\right)$ as recommended [25].

For the two spectral bands (green and red), we obtain 2 new bands X and Y from (1).

$$
\begin{aligned}
& X=\ln \left[\rho_{s}\left(\lambda_{g}\right)-\rho_{w}\left(\lambda_{g}\right)\right]=\ln \left[\rho_{b}\left(\lambda_{g}\right)-\rho_{w}\left(\lambda_{g}\right)\right]-2 k\left(\lambda_{g}\right) z \\
& Y=\ln \left[\rho_{s}\left(\lambda_{r}\right)-\rho_{w}\left(\lambda_{r}\right)\right]=\ln \left[\rho_{b}\left(\lambda_{r}\right)-\rho_{w}\left(\lambda_{r}\right)\right]-2 k\left(\lambda_{r}\right) z
\end{aligned}
$$

$\mathrm{Y}$ is then a linear expression of $\mathrm{X}$ whose slope equals the attenuation ratio of red and green regions $\left(\mathrm{k}\left(\lambda_{\mathrm{r}}\right) / \mathrm{k}\left(\lambda_{\mathrm{g}}\right)\right)$. This slope does not depend on the sea bottom cover, unlike the $\mathrm{y}$ intercept.

This theoretical result is confirmed by the plot, on the same graph of different points corresponding to the different sites (different depths). We obtain a line whose slope equals the attenuation ratio of red and green regions (Fig. 1).

\section{[insert Figure 1]}

The rotation of axes with an angle of $\mathrm{k}\left(\lambda_{\mathrm{r}}\right) / \mathrm{k}\left(\lambda_{\mathrm{g}}\right)$ ratio, provides 2 new images. This rotation aims at separating the influence of depth from other influences contributing to the measured reflectance (such as the seabed and the water colours). The depth-dependent image is the one along the axis marked "z". It is also an inversed image of the underwater topography. Several pixels corresponding to different known depths are required to compute the linear relation: minimum 2 but several known depths well distributed between 0 and 40m is advised [25]. This calibration with real depths avoids the need of tidal correction. 


\section{Data}

\subsection{Images}

A panel of 7 MERIS images full resolution has been compared. One was acquired in 2004, five were acquired in 2008, and one in 2009. All the images were chosen because of their low $\%$ of cloudy coverage. All images were co-registered on the first image acquired in 2004. They are in reflectance (level 2 product), corrected from the atmospheric effect. The level 2 product contains also chlorophyll maps: algal 1 and algal 2 for respectively case 1 and case 2 waters. Algal 1 is obtained by a polynomial function of band ratio [32] when algal 2 is provided by a neural network [33]. Compared to in situ water measurements, we notice an overestimation of chlorophyll concentration provided by algal 2 . We think that it is due to seabed in shallow water which influences the sea surface reflectance and also absorbing substances like blue-absorbing material like detritus or mineral colored particles which lead to higher chlorophyll concentration than real in situ [27]. But a relative map is here sufficient to explain the variation of attenuation and then the error of bathymetric estimation. Figure 2 shows an example of MERIS images acquired on 8 January 2004.

\section{[insert Figure 2]}

The optimal pair of bands chosen for bathymetric estimation is band $4(510 \mathrm{~nm})$ and band 5 $(560 \mathrm{~nm})$ as advised by Minghelli-Roman et $a l$. [34] for MERIS images.

\subsection{Validation data}

The validation data have been provided by digitized isobaths from the Service Hydrographique et Océanographique de la Marine, France) (SHOM) used as ground truth to be compared to model-derived values (figure 3a). The SHOM bathymetric map was also co- 
registered on the reference image of 2004. The co-registration required a resampling process operated by a pixel aggregate method. Three transects were defined to validate the results. These transects are reported on figure 2 . The first transect $\left(T_{1}\right)$ was chosen on the training area for the bathymetric model, it contains 94 pixels $\left(28.2 \mathrm{~km}\right.$ length). The second transect $\left(\mathrm{T}_{2}\right)$ was chosen on a different area but on the same side of the lagoon, it contains 146 pixels (43.8 km length). The third transect $\left(\mathrm{T}_{3}\right)$ was chosen in the Eastern part of the lagoon, on the eastern coast of the island, it contains 64 pixels $(19.2 \mathrm{~km}$ length). The choice of these transects was made to evaluate the robustness of the method first to the variation of chlorophyll concentration and then to the variation of water diffuse attenuation in the lagoon.

The error will be measured by the mean of 2 parameters: the Root Mean Squared Error (RMSE) and the Mean absolute Percentage Error (MAPE).

$$
\operatorname{RMSE}(\theta)=\sqrt{E\left[(\theta-\hat{\theta})^{2}\right]} \text { and } \operatorname{MAPE}(\theta)=E\left[\left|\frac{\theta-\hat{\theta}}{\theta}\right|\right]
$$

RMSE provides an absolute error in meters and MAPE gives a relative error in \%.

\section{Results}

The training area for the bathymetric model was the same for all the images located on the first transect on figure 3. On figure 4, can visually be compared the depth estimation map (fig. 3b.) to the SHOM map (fig. 3a.). These 2 maps provide the depth in meters for each pixel and have been associated to the same colour table from white (weak depth) to deep blue (high depth).

\section{[insert Figure 3]}

The visual comparison can be only operated inside the lagoon because the depth estimation method is not valid beyond $50 \mathrm{~m}$ depth (too deep for the seabed to be of influence). Note that 
the white patch in the south (indicated by the arrow in Fig. 3a.) corresponds to a zone of previously unknown bathymetry. The bathymetry there is then given for the first time with MERIS.

Table 1 provides the RMSE and the mean relative error between each image and the bathymetric reference on the 3 transects.

\section{[insert Table 1]}

Table 2 provides the mean $(\mathrm{m})$ of the chlorophyll concentration for the 3 transects provided by the MERIS level 2 product. The variation of chlorophyll concentration within the training transect or between the 3 transects can explain the error on bathymetric estimation reported in table 1 .

\section{[insert Table 2]}

The two images presented in figure 4 were subtracted for each pixel and the absolute value of the difference provides the map of error presented in figure 4. A color scale was applied in order to better visualise the error (blue for weak errors, green for middle errors and red for high errors).

\section{[insert Figure 4]}

This map allows to analyse spatially the error of estimation in order to explain the variation.

\section{Discussion}

The depth estimation obtained from 8 January 2004 image can visually be compared to the SHOM map (fig. 3). Strong similarities in the depth topography can be noticed between the two maps inside the lagoon. The highest differences appear in the bays and in the Eastern lagoon and these errors will be explained. 
If we compare the depth values numerically on the training transect (table 1) the first image ( 8 January 2004) provides the best estimation with a RMSE of $5.6 \mathrm{~m}$ and a MAPE of $16 \%$. Compared to the other images, this image provides the better results because the mean chlorophyll concentration is the lowest of the 7 images: $0.63 \mathrm{mg} \cdot \mathrm{m}^{-3}$ on the $1^{\text {st }}$ transect (table 2).

This result is reasonably acceptable when the chlorophyll concentration is low but when the concentration of chlorophyll increases (in the other images) we can notice an increase of depth estimation error (tables 1 and $2,1^{\text {st }}$ line).

If the RMSE on depth estimation is plotted versus the mean chlorophyll concentration on the first transect of all images, we notice a strong correlation between these two parameters as shown on figure 5. The RMSE on depth estimation increases linearly with the chlorophyll concentration. When the chlorophyll concentration increases of $0.1 \mathrm{mg} \cdot \mathrm{m}^{-3}$, the RMSE increases of $0.31 \mathrm{~m}$.

\section{[insert Figure 5]}

This figure shows also that the best bathymetric map is obtained with the image whose water is the "clearest" (image I1 acquired on the 8 January 2004). When the choice is possible on the image, the image containing the "clearest" water on the training area the must be retained.

Concerning variation of attenuation in one image, if the bathymetry results are compared (table 1) on the $2^{\text {nd }}$ transect, the second image (18 June 2008) provides the best estimation with a RMSE of $5.8 \mathrm{~m}$ and a MAPE of $22 \%$. We explain this result by the spatial variation of attenuation in the same image, more important between the $1^{\text {st }}$ and $2^{\text {nd }}$ transects for the first 
image than for the second because the variation of mean chlorophyll concentration is higher for the first image $\left(-0.20 \mathrm{mg} \cdot \mathrm{m}^{-3}\right)$ than for the second $\left(-0.13 \mathrm{mg} \cdot \mathrm{m}^{-3}\right)$. When the variation of concentration of chlorophyll increases (or decreases) in the same image, the attenuation is no more homogenous and the error on depth estimation increases.

If we consider the $3^{\text {rd }}$ transect, located on the Eastern side of the lagoon, the error of estimation is high for all the images (>29.2 $\mathrm{m}$ for the RMSE, and $>56 \%$ for the MAPE) because the attenuation is much lower on the Eastern side than on the Western. The comparison of the mean chlorophyll concentration between the $1^{\text {st }}$ and the $3^{\text {rd }}$ transect can explain this important error. The error is the lowest when the chlorophyll concentration variation is the lowest too, for the $2^{\text {nd }}\left(-0.31 \mathrm{mg} \cdot \mathrm{m}^{-3}\right)$ and the $3^{\text {rd }}$ image $\left(-0.43 \mathrm{mg} \cdot \mathrm{m}^{-3}\right)$.

Figure 4 confirms visually, with the clearest image (8 January 2004), that the error is the highest on the eastern part of the lagoon than on the western one. We can also notice on this map that the highest errors on the western side are located in the bays where the water quality is different due to the rivers entrance and on the shallow waters close to the reef where the bottom has a strong influence on the surface reflectance. Between the western and the eastern reefs, on the south part of the lagoon, the nickel industries reject brown clay in the water and the attenuation is then also modified in this area, explaining once more the error of bathymetric estimation.

The results obtained with the 7 MERIS images lead to advise a low concentration of chlorophyll ( $<1$ mg.m-3) and a weak variation of chlorophyll in the image $(<10 \%)$ to keep the RMSE obtained in the training area all over the image (variation of maximum 15.5\%). 


\section{Conclusion}

In this paper, we tested the limit of the bathymetric estimation method based on the rotation of 2 spectral bands (red and green) on an optically complex area which is the lagoon on New Caledonia. We compared the results obtained with 7 different MERIS images acquired in 2004, 2008 and 2009. This comparison allowed studying the influence of chlorophyll concentration on the bathymetric estimation error. The error is due to the water composition and to its spatial variation within the lagoon. We can then advise to use this method only in oligotrophic periods and regions where the chlorophyll concentration is low $(<1 \mathrm{mg} . \mathrm{m}-3)$ and constant $(<10 \%$ of variation in the image) to limit the error of bathymetric estimation all over the image.

\section{Acknowledgment}

We are grateful to the European Space Agency for providing the ENVISAT data used in this study (project AOE.822). We also thank Pascal Douillet (IRD) and Romain Legendre (Ifremer) for the bathymetric validation data compiled from SHOM/IRD/ZONECO in Nouméa (Service Hydrographique et Océanographique de la Marine/Institut de Recherche pour le Développement, ZOne ECOnomique Research program). This work was partly supported by PNTS-INSU VALHYBIO project. 


\section{References}

[1] E. Kammerer, D. Charlot, V. Guillaudeux and P. Michaux, "Comparative study of shallow water multibeam imagery for cleaning bathymetry sounding errors", OCEANS MTS/IEEE Conference and Exhibition, vol. 4, pp. 2124-2128, 2001.

[2] J.S. Bird, J.S., G.K. Mullins, "Analysis of swath bathymetry sonar accuracy", IEEE J. Oceanic Engineering, vol. 30, pp. 372-390, 2005.

[3] F.C. Polcyn, W.L. Brown W.L., I.J. Sattinger, I.J., "The measurement of water depth by remote sensing", Report no. 8973-26-F. Ann Arbor, MI, USA: Willow Run Laboratories, Michigan University, 1970.

[4] L.W. Brown, F.C. Polcyn, S.R. Stewart, "A method for calculating water depth, attenuation coefficients and bottom reflectance characteristics", $7^{\text {th }}$ Int. Symp. on Remote Sensing of Environment. Ann Arbor. Michigan, pp. 663-680, 1971.

[5] D.R. Lyzenga, "Passive remote sensing techniques for mapping water depth and bottom features", Applied Optics, vol. 17, pp. 379-383, 1978.

[6] W.D. Philpot, "Bathymetric mapping with passive multispectral imagery", Applied optics, vol. 28, pp. 1569-1578, 1989.

[7] D.R. Lyzenga, "Shallow-water bathymetry using combined lidar and passive multispectrale scanner data”, Int. J. Remote Sensing, vol. 6, pp. 115-125, 1985.

[8] F.C. Polcyn, D.R. Lyzenga, "Calculation of water depth from ERTS-MSS data", Symposium of Significant Results from ERTS-1, NASA Spec, Publ. SP327, 1973.

[9] V. Lafon, J.M. Froidefond, F. Lahet, F., P. Castaing, "SPOT shallow water bathymetry of a moderately turbid tidal inlet based on field measurements", Remote Sensing Env., vol. 81, pp. 136-148, 2002. 
[10] S. Andréfouët, P. Kramer, D. Torres-Pulliza, K.E. Joyce E.J. Hochberg, R. Garza-Pérez P.J. Mumby, B. Riegl, H. Yamano, W.H. White, M. Zubia, J.C. Brock, S.R. Phinn, A. Naseer, B.G. Hatcher, F.E. Muller-Karger, "Multi-site evaluation of IKONOS data for classification of tropical coral reef environments", Remote Sensing of Environment, vol. 88, pp. 128-143, 2003.

[11] S.M. Adler-Golden, P. K. Acharya, A. Berk, M. W. Matthew and D. Gorodetzky "Remote Bathymetry of the Littoral Zone From AVIRIS, LASH, and QuickBird Imagery", IEEE Trans.Geosci.Remote Sens., vol. 43, pp. 337-347, 2005

[12] A. Albert and P. Gege, "Inversion of irradiance and remote sensing reflectance in shallow water between 400 and $800 \mathrm{~nm}$ for calculations of water and bottom properties", Applied Optics, vol. 45, pp. 2331-2343, 2006.

[13] Z. Lee, Z., K. L. Carder, C. D. Mobley, R. G. Steward and J. F. Patch, "Hyperspectral remote sensing for shallow waters: 2 . deriving bottom depths and water properties by optimization", Applied Optics, vol. 38, pp. 3831-3843, 1999.

[14] Z. Lee, K. L. Carder, R. F. Chen and T. G. Peacock, "Properties of the water column and bottom derived from Airborne Visible Imaging Spectrometer (AVIRIS) data", Journal of Geophysical Research Ocean, vol. 106, pp. 11639-11651, 2001

[15] E. M. Louchard, R. P. Reid, F. C. Stephens, C. O. Davis, R. A. Leathers and T. V. Downes, "Optical remote sensing of benthic habitats and bathymetry in coastal environments at Lee Stocking Island, Bahamas: A comparative spectral classification approach", Limnology and Oceanography, vol. 48, pp. 511-521, 2003.

[16] C. D. Mobley, L. Sundman, C. O. Davis, J. H. Bowles, T. V. Downes, R. A. Leathers, M. J. Montes, W. P. Bisset, D. D. R. Kohler, R. P. Reid, E. M. Louchard and A. Gleason, "Interpretation of hyperspectral remote-sensing imagery by spectrum matching and look-up tables", Applied Optics, vol. 44, pp. 3576-3592, 2005. 
[17] M.L. McIntyre, D. F. Naar, K. L. Carder, B. T. Donahue and D. J. Mallinson, "Coastal bathymetry from hyperspectral remote sensing data: comparisons with high resolution multibeam bathymetry" Marine Geophysical Researches, vol. 27, pp. 128-136, 2006

[18] C. Giardino, M. Bartoli, G. Candiani, M. Bresciani and L. Pellegrini, "Recent changes in macrophyte colonisation patterns: an imaging spectrometry-based evaluation of the southern Lake Garda (northern Italy)", Journal of Applied Remote Sensing 1: 011509, 2007.

[19] J. Goodman and S. L. Ustin, "Classification of benthic composition in a coral reef environment using spectral unmixing", Journal of Applied Remote Sensing 1: 011501, 2007

[20] W.M. Klonowski, P. R. C. S. Fearns and M. J. Lynch, "Retrieving key benthic cover types and bathymetry from hyperspectral imagery", Journal of Applied Remote Sensing, 1: 011505,2007

[21] J. Goodman, Z. Lee, and S. L. Ustin, "Influence of atmospheric and sea-surface corrections on the accuracy of the retrieval of bottom depth and reflectance using a semi-analytical model. Classification of benthic composition in a coral reef environment using spectral unmixing", Journal of Applied Remote Sensing, pp. 1: 011501, 2008.

[22] V. E. Brando, J.M. Anstee, A.G. Wettle, M. Dekker, S.R. Phinn and C. Roelfsema, "A Physics Based Retrieval and Quality Assessment of Bathymetry from Suboptimal Hyperspectral Data," Rem. Sens. Environm., vol. 113 , pp. 755-770, 2009.

[23] J. Neveux, M. Tenório, S. Jacquet, J-P Torréton, P. Douillet, S. Ouillon; C. Dupouy , "Chlorophylls and phycoerythrins add markers of environmental forcings including Cyclone Erica effect (March 2003) on phytoplankton in the South Western lagoon of New Caledonia and Oceanic adjacent area", Int. J. Oceanography. doi:10.1155/2009/232513, 2009.

[24] S. Jacquet, B. Delesalle, J.P. Torréton, J. Blanchot, "Response of phytoplankton communities to increased anthropogenic influences (southwestern lagoon, New 
Caledonia)", Mar. Ecol. Progr. Series, vol. 320, pp. 65-78, doi: 10.3354/meps320065, 2006.

[25] S. Ouillon, P. Douillet, A. Petrenko, J. Neveux, C. Dupouy, J.M. Froidefond, S. Andréfouët, A. Muñoz-Caravaca, "Optical algorithms at satellite wavelengths for total suspended matter in tropical coastal waters", Sensors 8, pp. 4165-4185, DOI: 10.3390/sensors, 2008.

[26] S. Ouillon, P. Douillet, J.P. Lefebvre, R. Le Gendre, A. Jouon, P. Bonneton, J.M. Fernandez, C. Chevillon, O. Magand, J. Lefèvre, P. Le Hir, R. Laganier, F. Dumas, P. Marchesiello, A. Bel Madani, S. Andréfouët, J.Y. Panché, R. Fichez, "Circulation and suspended sediment transport in a coral reef lagoon: the southwest lagoon of New Caledonia”, Marine Pollution Bulletin, vol. 61, pp: 269-296, 2010.

[27] J.P. Torréton, E. Rochelle-Newall, A. Jouon, V. Faure, S. Jacquet, P. Douillet, "Correspondence between the distribution of hydrodynamic time parameters and the distribution of biological and chemical variables in a semi-enclosed coral reef lagoon", Estuarine, Coastal and Shelf Science, vol. 74, pp. 667-677, 2007.

[28] C. Dupouy, J. Neveux, S. Ouillon, R. Frouin, H. Murakami, S. Hochard, G. Dirberg, "Inherent optical properties and satellite retrieval of chlorophyll concentration in the lagoon and open ocean waters of New Caledonia", Marine Pollution Bulletin, vol. 61, pp. 503-518, doi:10.1016/j.marpolbul.2010.06.039, 2010

[29] M. Rast, J.L. Bézy and S. Bruzzi, “The ESA Medium Resolution Imaging Spectrometer MERIS-a review of the instrument and its mission", Int. J. Remote Sensing, vol. 20, pp. 1681-1702, 1999

[30] S. Maritorena, A. Morel, B. Gentili, "Diffuse reflectance of oceanic shallow waters: Influence of water depth and bottom albedo", Limnology and Oceanography, vol. 39, pp. 1689-1703, 1994.

[31] N.G. Jerlov., Marine optics, Elsevier, Amsterdam, 1976. 
[32] A. Minghelli-Roman, A. Goreac, S. Mathieu, M. Spigai, P. Gouton, 2009, Comparison of Bathymetric estimation using different satellite images in coastal sea waters, International Journal of Remote Sensing, vol. 30, pp. 5737-5750.

S. Jay, M. Guillaume, J. Blanc-Talon, 2012, Underwater Target Detection With Hyperspectral Data: Solutions for Both Known and Unknown Water Quality, IEEE Journal of Selected Topics in Applied Earth Observations and Remote Sensing, vol. 5 , pp. 1213 1221.

R.Y. Setiawan, A. Habibi, 2011, Satellite Detection of Summer Chlorophyll-a Bloom in the Gulf of Tomini, IEEE Journal of Selected Topics in Applied Earth Observations and Remote Sensing, vol. 4 , pp. $944-948$. 


\section{Figures Captions}

Fig. 1: $\quad$ Spectral rotation for bathymetric estimation [6]

Fig. 2: $\quad$ Example of MERIS images level 2 (bands 1, 5, 10) acquired on 8 January 2004 and transects of validation

Fig. 3: $\quad$ (a) Bathymetric map of SHOM and (b) bathymetric estimation obtained with MERIS image acquired on 8 January 2004. Note that the white patch in the south corresponds to a zone of unknown bathymetry. The bathymetry there is then defined for the first time with MERIS.

Fig. 4: Absolute error of bathymetric estimation obtained with MERIS image acquired on 8 January 2004

Fig. 5: $\quad$ Correlation between the RMSE of depth estimation and mean MERIS chlorophyll concentration on the $1^{\text {st }}$ transect for all images (I1-I7)

Table I : Comparison of estimated depth obtained with all images with SHOM measurements on 3 transects located on figure 3

Table II : $\quad$ Mean of chlorophyll concentration on the 3 transects for the 7 images 
Table I : Comparison of estimated depth (obtained with the 7 images) with SHOM measurements on 3 transects located on figure 3

(Root Mean Square error (m) and Mean absolute Percentage Error (\%))

\begin{tabular}{|c|c|c|c|c|c|c|c|}
\hline Depth (m) & $\begin{array}{l}8 / 1 / 2004 \\
\text { I1 }\end{array}$ & $\begin{array}{l}18 / 6 / 2008 \\
\text { I2 }\end{array}$ & $\begin{array}{l}13 / 07 / 2008 \\
\text { I3 }\end{array}$ & $\begin{array}{l}20 / 10 / 2008 \\
\text { I4 }\end{array}$ & $\begin{array}{l}2 / 11 / 2008 \\
\text { I5 }\end{array}$ & $\begin{array}{l}17 / 1 / 2009 \\
\text { I6 }\end{array}$ & $\begin{array}{l}24 / 2 / 2009 \\
\text { I7 }\end{array}$ \\
\hline $\begin{array}{l}\text { Transect } 1 \\
\text { (94 pixels) }\end{array}$ & $\begin{array}{l}\text { RMSE :5.9 } \\
\text { MAPE : } 16 \%\end{array}$ & $\begin{array}{l}6.1 \\
19 \%\end{array}$ & $\begin{array}{l}7.2 \\
21 \%\end{array}$ & $\begin{array}{l}7.3 \\
22 \%\end{array}$ & $\begin{array}{l}6.3 \\
19 \%\end{array}$ & $\begin{array}{l}9.0 \\
25 \%\end{array}$ & $\begin{array}{l}6.6 \\
19 \%\end{array}$ \\
\hline $\begin{array}{l}\text { Transect } 2 \\
(146 \\
\text { pixels })\end{array}$ & $\begin{array}{l}8.8 \\
38 \%\end{array}$ & $\begin{array}{l}5.8 \\
22 \%\end{array}$ & $\begin{array}{l}10.4 \\
45 \%\end{array}$ & $\begin{array}{l}11.3 \\
47 \%\end{array}$ & $\begin{array}{l}12.3 \\
53 \%\end{array}$ & $\begin{array}{l}9.8 \\
42 \%\end{array}$ & $\begin{array}{l}10.5 \\
44 \%\end{array}$ \\
\hline $\begin{array}{l}\text { Transect3 } \\
\text { (64 pixels) }\end{array}$ & $\begin{array}{l}35.6 \\
67 \%\end{array}$ & $\begin{array}{l}31.3 \\
56 \%\end{array}$ & $\begin{array}{l}29.2 \\
69 \%\end{array}$ & $\begin{array}{l}47.3 \\
91 \%\end{array}$ & $\begin{array}{l}42.8 \\
79 \%\end{array}$ & $\begin{array}{l}53.0 \\
113 \%\end{array}$ & $\begin{array}{l}47.0 \\
84 \%\end{array}$ \\
\hline
\end{tabular}

Table II : Mean of chlorophyll concentration on the 3 transects for the 7 images

\begin{tabular}{|l|l|l|l|l|l|l|l|}
\hline Mean Chl & $8 / 1 / 2004$ & $18 / 6 / 2008$ & $13 / 07 / 2008$ & $20 / 10 / 2008$ & $2 / 11 / 2008$ & $17 / 1 / 2009$ & $24 / 2 / 2009$ \\
$(\mathrm{mg} / \mathrm{m} 3)$ & I1 & I2 & I3 & I4 & I5 & I6 & I7 \\
\hline $\begin{array}{l}\text { Transect 1 } \\
\text { (94 pixels) }\end{array}$ & 0.63 & 0.64 & 1.11 & 1.28 & 0.96 & 1.35 & 0.79 \\
\hline $\begin{array}{l}\text { Transect 2 } \\
(146 \text { pixels })\end{array}$ & 0.43 & 0.51 & 0.66 & 0.50 & 0.35 & 0.54 & 0.43 \\
\hline $\begin{array}{l}\text { Transect3 } \\
(64 \text { pixels })\end{array}$ & 0.09 & 0.33 & 0.68 & 0.34 & 0.2 & 0.15 & 0.22 \\
\hline
\end{tabular}




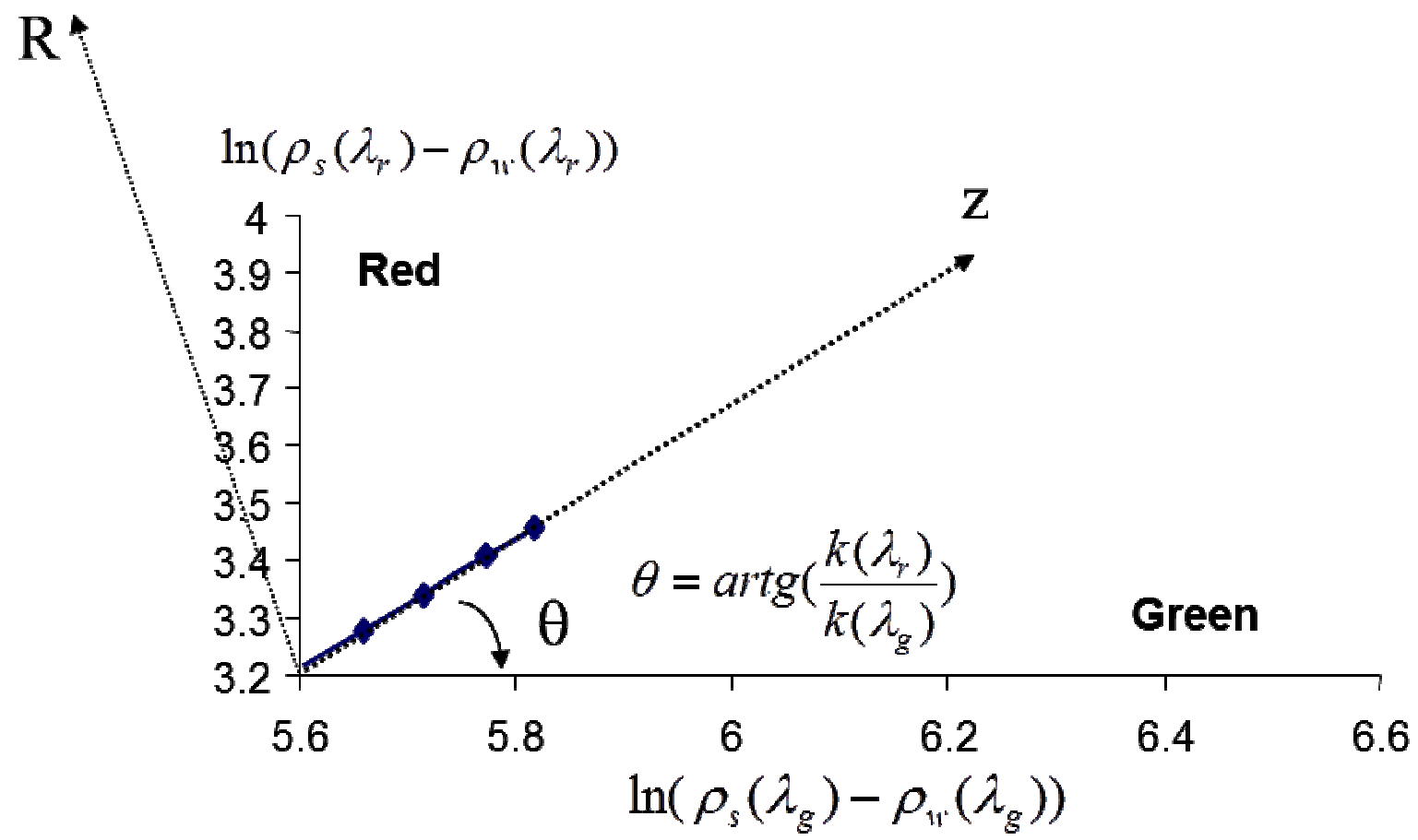

Figure 1 : Spectral rotation for bathymetric estimation [6] 


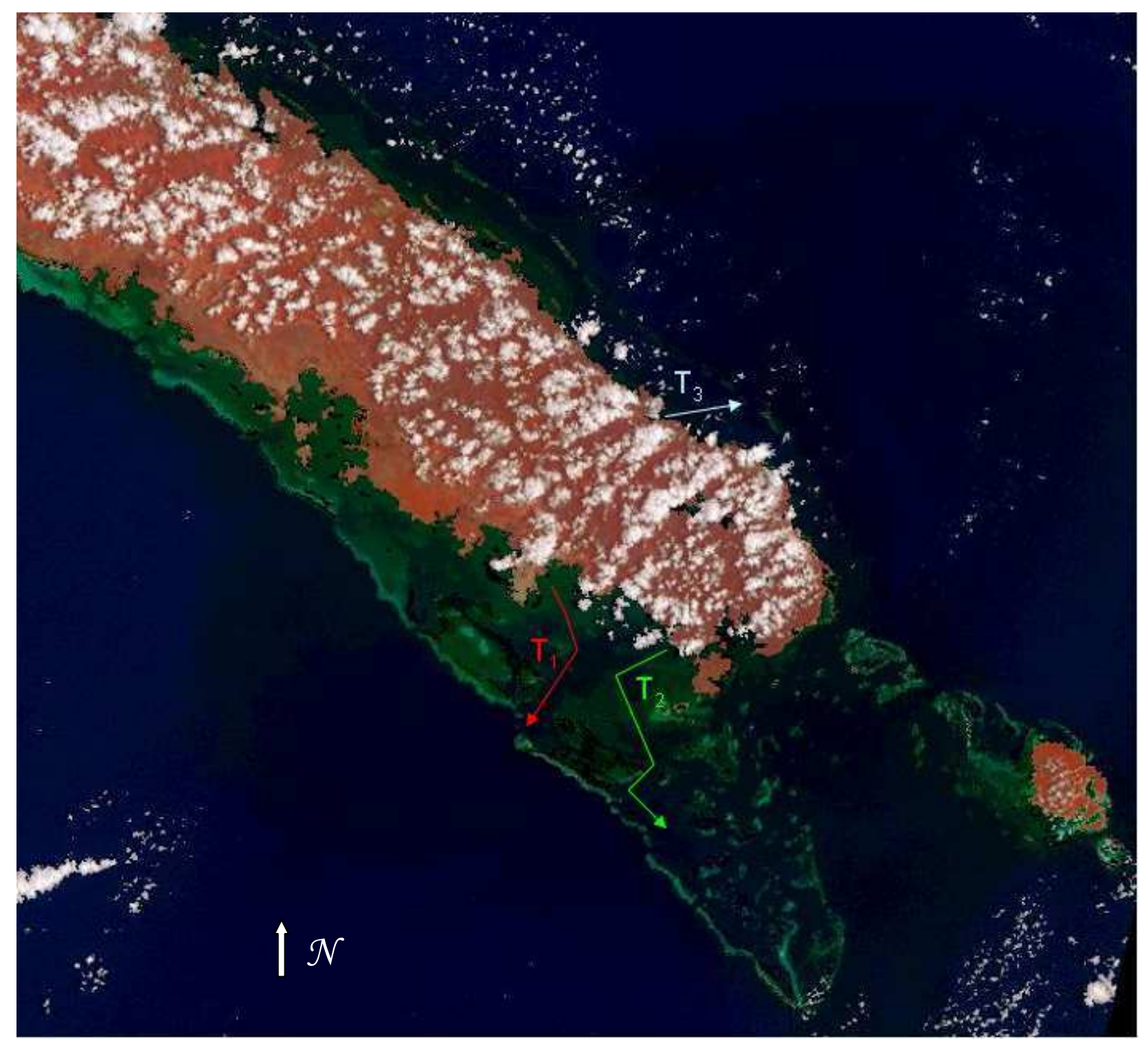

Figure 2 : Example of MERIS images level 2 (bands 1,5,10) acquired on 8 January 2004 


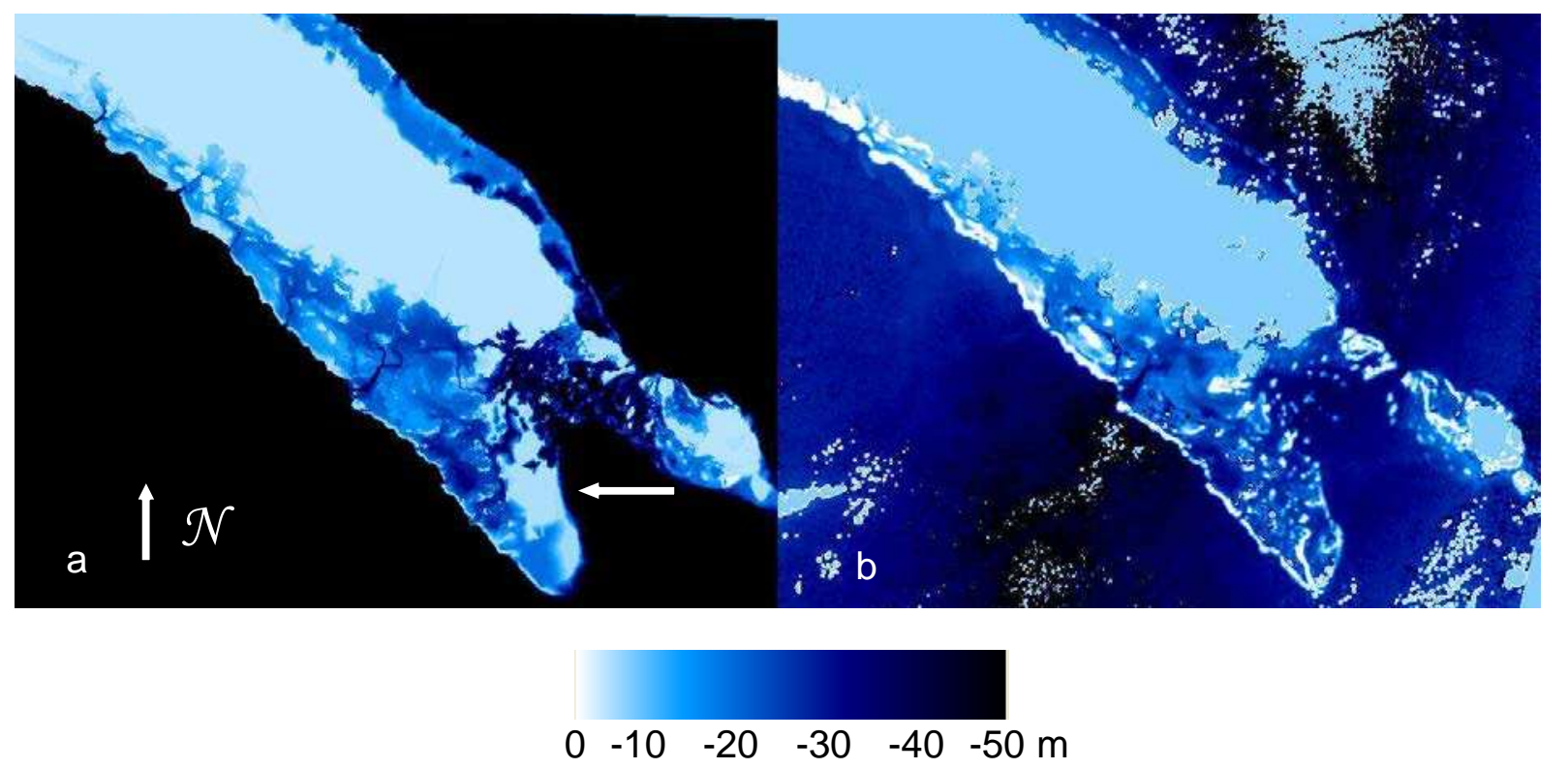

Figure 3 : (a) Bathymetric map of SHOM and (b) bathymetric estimation obtained with MERIS image acquired on 8 January 2004. 


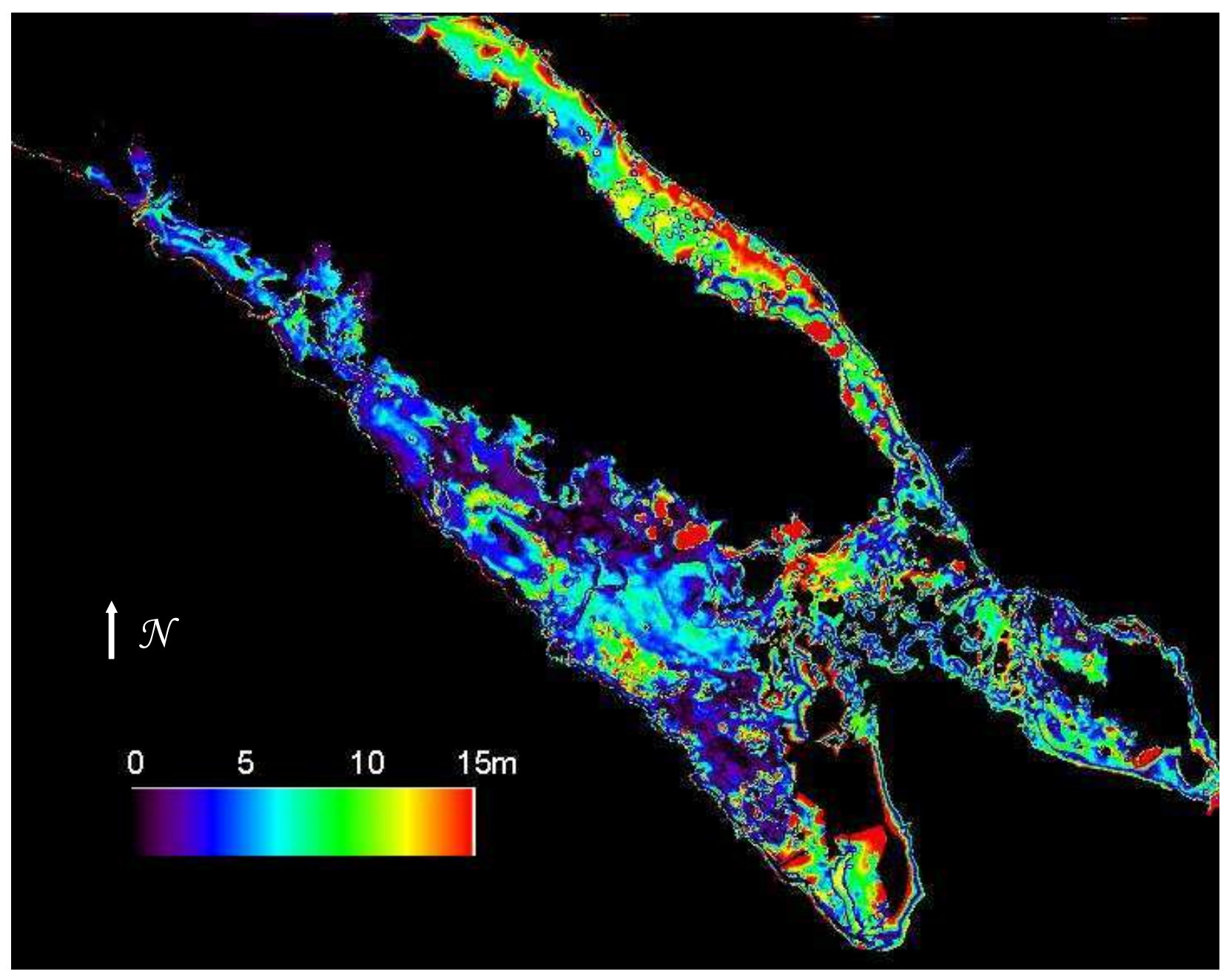

Figure 4 : Absolute error of bathymetric estimation obtained with MERIS image acquired on 8 January 2004 


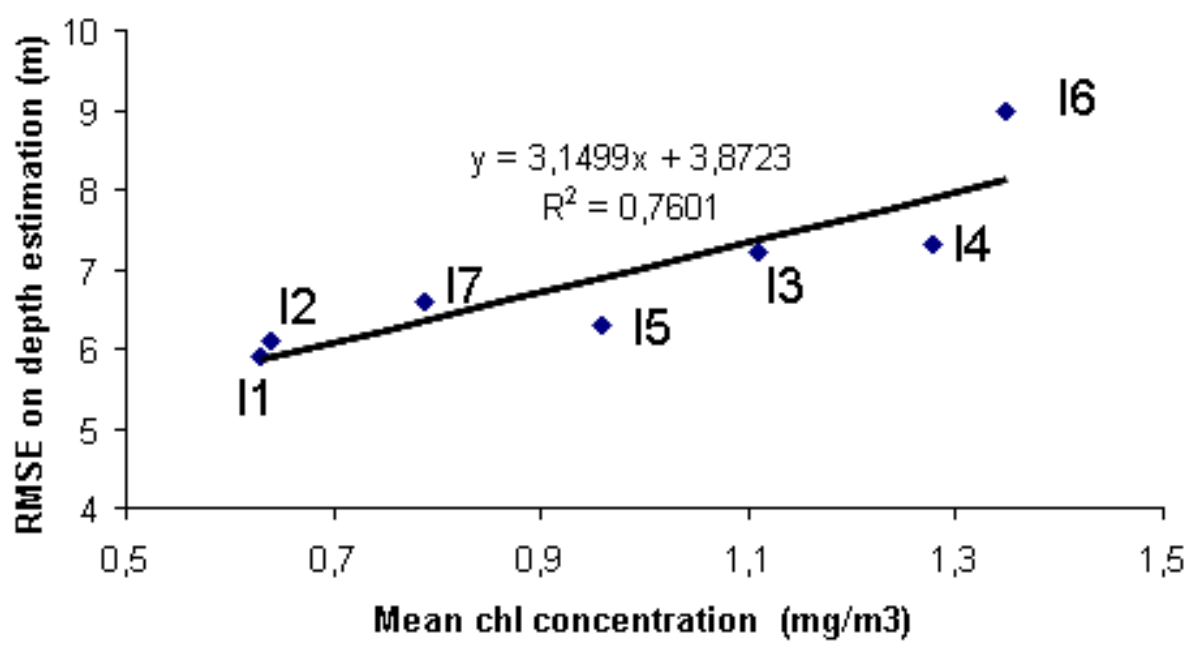

Figure 5 : Correlation between the RMSE of depth estimation and mean MERIS chlorophyll concentration on the $1^{\text {st }}$ transect $\left(\mathrm{T}_{1}\right)$ for all images (I1-I7) 